М.Г.Сычева, Т.И.Грушина

Медикаментозные средства предотвращения и минимизации лучевых повреждений легких

ГБУ "Московский научно-практический центр медицинской реабилитации, восстановительной и спортивной медицины" Департамента здравоохранения Москвы: 107120, Москва, Земляной Вал, 53

\title{
M.G.Sycheva, T.I.Grushina \\ Drug therapy to prevent and diminish radiation injury of the lungs
}

Key words: radiotherapy, radiation induced lung injury, radiation pneumonitis, radiation fibrosis, medications, radioprotectors, mitigators. Ключевые слова: лучевая терапия, радиационно-индуцированные повреждения легких, пневмонит, пневмофиброз, медикаментозные средства, радиопротекторы, митигаторы.

Локальным методом лечения злокачественных опухолей является лучевая терапия. Ионизирующая радиация вызывает цепь биофизических, биохимических, функциональных и морфологических изменений как в опухолевых клетках, так и в здоровых тканях.

В ответ на облучение в легочной ткани происходит апоптотическая деградация ДНК делящихся клеток, истощение (старение) стволовых клеток, фиброз стромальных элементов с развитием артериокапиллярного фиброза, увеличение концентрации активных форм кислорода и их токсическое действие на клетки паренхимы, приток клеток воспаления (макрофаги и лимфоциты) и волны цитокинов ("цитокиновая буря"). Важную роль в развитии радиационного повреждения легких играет стрессовый ответ клеток - клеточная активация инициирует процесс, включающий цитокины и факторы роста основной фактор роста фибробластов, интерлейкин-1, трансформирующий фактор роста- $\beta$ (transforming growth factors - TGF- $\beta$ ). Простагландиновый синтез также перестает быть регулируемым. Создается замкнутый цикл воспаления и хронического окислительного стресса. Исходом каскада молекулярных и клеточных событий является развитие лучевых повреждений легких [1-4].

С целью предотвращения и минимизации лучевых повреждений здоровых тканей, наряду с разработкой новых видов и технологий лучевой терапии, проводится поиск эффективных медикаментозных средств, применяемых в зависимости от действия на легочную ткань и сроков их назначения [5-8], таких как:

- радиопротекторы - предотвращающие повреждения нормальных тканей (до или во время облучения);

- радиомитигаторы (смягчители) - минимизирующие степень повреждения нормальных тканей (во время или после облучения, но до появления симптомов радиационного повреждения);
- терапевтические - снижающие тяжесть повреждения нормальных тканей (после облучения при появлении симптомов радиотоксичности).

На сегодняшний день амифостин (этиол) является наиболее эффективным и проверенным лекарственным средством с цито- и радиопротективным действием [9], которое складывается из антиоксидантного эффекта, защиты ДНК и ускорения процессов восстановления тканей. Результаты нескольких клинических исследований защитного эффекта амифостина в известной степени противоречивы.

В 1-й фазе рандомизированного исследования [10, 11] было выявлено достоверное $(p<0,001)$ снижение числа случаев развития тяжелых пневмонитов ( $\geq$ II степени по шкале Радиотерапевтической онкологической группы и Европейской организации по исследованию и лечению рака - RTOG / EORTC, 1998) [12] у больных немелкоклеточным раком легкого, получавших амифостин (340 мг / м²) в течение 5 дней в неделю за 15 мин до сеанса лучевой терапии, по сравнению с группой больных, получавших только лучевую терапию (9 \% и $43 \%$ соответственно). Во 2 -й фазе у больных $(n=36)$, которым проводилась химиолучевая терапия в сочетании с амифостином, через 3 мес. после ее окончания случаи лучевого пневмонита встречались значительно реже, чем у больных $(n=32)$, получивших только химиолучевую терапию $(p=0,009)$. Через 6 мес. после лечения амифостином пневмофиброз отмечен у $28 \%$ пациентов по сравнению с 53 \% больных, не получавших препарата $(p<0,05)$.

В рандомизированном исследовании [13] у больных немелкоклеточным раком легкого II и III стадии, получавших химиолучевую терапию одновременно с амифостином (500 мг внутривенно 2 раза в неделю), лучевой пневмонит развился у $3,7 \%$ vs $23 \%$ больных, получавших только химиолучевую терапию $(p<0,037)$. Показатели средней продолжительности 
жизни были выше у пациентов, получающих амифостин (26 мес. vs 15 мес.).

Показано также, что в результате терапии амифостином до начала лучевой терапии произошло снижение уровней макрофагов и экспрессии тканевого TGF- $\beta_{1}$, а также предотвращено снижение диффузионной способности легких по монооксиду углерода $\left(\mathrm{DL}_{\mathrm{Co}}\right)$ при химиолучевой терапии $[14,15]$.

По результатам крупного рандомизированного исследования [16] радиопротективный эффект амифостина не подтвердился у больных немелкоклеточным раком легких, получавших химиолучевую терапию, по сравнению с контрольной группой, хотя по данным самооценки пациентов, применение амифостина давало определенные преимущества.

Показано радиопротективное действие пентоксифиллина (производная ксантина) - препарата, улучшающего микроциркуляцию и реологические свойства крови. В двойном слепом рандомизированном исследовании [17] больные $(n=40)$ раком легкого и раком молочной железы рандомизированы в 2 группы: получавшие в течение всего периода лучевой терапии пентоксифиллин по 400 мг 3 раза в день или плацебо. Было достоверно доказано уменьшение степени выраженности ранних и поздних лучевых повреждений легких при профилактическом приеме пентоксифиллина. Применение пентоксифиллина в той же дозе в комбинации с витамином Е (400 мг в сутки) оказывало более заметный протективный эффект [18, 19].

При использовании ингибиторов ангиотензинпревращающего фермента (АПФ) или антагонистов рецепторов ангиотензина II 1-го и 2-го типов, по некоторым данным, уменьшались или вовсе отсутствовали функциональные повреждения почек, легких и кожи у животных в результате лучевой терапии [20-22]. В последнее время ингибиторы АПФ признаны более эффективными радиосмягчителями, чем блокаторы рецепторов ангиотензина [23, 24]. В дополнение к своему благоприятному влиянию на сердечно-сосудистую систему отмечена способность каптоприла (тиолсодержащий препарат) удалять свободные радикалы и поддерживать функцию эндотелиальных клеток в облученных тканях [23]. В момент начала или спустя 2 нед. после облучения грудной клетки крысам давали растворенный в питьевой воде каптоприл [25]. В результате действия препарата уменьшались сосудистые повреждения легких, причем этот радиосмягчительный эффект наблюдался даже в случае если лекарственная терапия начиналась только через 2 нед. после лучевой терапии.

Под действием различных типов ингибиторов АПФ (фозиноприл, эналаприл, каптоприл), испытанных по отдельности или в комбинации с другими препаратами, замедлялось наступление пневмофиброза у мышей даже при назначении через 1 нед. после тотального облучением легких $[4,26]$. После терапии каптоприлом и эналаприлом (но не фозиноприлом) снижалась заболеваемость пневмонитом в период от 42 до 70 дней после тотального облучения легких. Следовательно, механизм действия ин- гибиторов АПФ может быть эффектом, характерным именно для этого класса лекарственных средств, не связанным со структурными заместителями, которые различаются у всех 3 препаратов. По результатам ретроспективного анализа среди больных раком легкого $(n=162)$, получавших химиолучевую терапию, у 2 \% пациентов, постоянно принимавших ингибиторы АПФ, отмечен лучевой пневмонит II степени и выше по сравнению с показателями в других группах $(11 \%)(p=0,032)$ [27].

В экспериментальном исследовании независимой комбинации лекарственных средств при добавлении каптоприла к EUK-207 (синтетический миметик супероксиддисмутазы-SOD-каталазы) выживаемость грызунов повысилась практически в 2 раза (86 \% vs $47 \%$ ), а при добавлении к этой комбинации статинов через 6 мес. после облучения грудной клетки отмечена 100\%-ная выживаемость [26].

Использование статинов - гиполипидемических средств, обладающих выраженными плейотропными эффектами (кардиоваскулопротективный, противовоспалительный, антитромботический) и улучшающих нарушенную функцию эндотелия - может оказать влияние на воспалительный компонент лучевых повреждений легких. В исследовании [28] после терапии ловастатином снижалась частота развития пневмонита и повышалась выживаемость у мышей, подвергшихся высокодозному облучению, независимо от того, назначался ли препарат сразу после облучения или 8 нед. спустя. Продемонстрирована также эффективность других статинов (симвастатин, правастатин) в снижении частоты развития пневмофиброза у ряда различных биологических моделей [29, 30].

Амброксол - секретолитик и стимулятор моторной функции дыхательных путей - обладает противовоспалительным действием, ингибируя хемотаксис нейтрофилов. Его действие на лучевые повреждения легких изучено в рандомизированном клиническом исследовании [31]. Наблюдались больные $(n=120)$ местнораспространенным раком легкого, получавшие лучевую терапию. Из них больные основной группы принимали амброксол внутрь в дозе 90 мг 3 раза в день в течение 3 мес. от начала лучевой терапии. Анализ клинических симптомов, лабораторных тестов и показателей $\mathrm{DL}_{\mathrm{CO}}$ дополнялся данными компьютерной томографии. Исследование показало, что при действии амброксола уменьшаются экспрессия TGF- $\beta_{1}$, фактора некроза опухоли- $\alpha$ (tumor necrosis factor $\alpha-\mathrm{TNF}-\alpha$ ), DLсо после лучевой терапии снижается до минимума.

Из-за недостаточного количества исследований остается неясной роль препаратов, используемых для предупреждения или смягчения лучевых повреждений легких и лечения идиопатического фиброза легких - N-ацетилцистеина [32] и нового средства с комбинированным противовоспалительным, антиоксидантным и антифиброзным эффектом - пирфенидона (Esbriet, Pirfenex) [33].

Инфликсимаб (Ремикейд), являющийся иммунодепрессантом с высоким аффинитетом к TNF- $\alpha$, используется в лечении аутоиммунных и воспалитель- 
ных заболеваний - ревматоидного артрита, псориаза, болезни Крона. По данным [34], при использовании препарата стабилизировались функциональные показатели легких и давление в легочной артерии у пациентов с пневмофиброзом и легочной гипертензией, ассоциированных с тяжелой системной склеродермией. Успешное применение препарата в лечении данных заболеваний послужило основанием для выяснения его возможного радиопротективного действия. Проводились исследования образцов цельной крови, стандартизированных по количеству лейкоцитов, у больных $(n=97)$ с опухолями в области головы и шеи, грудной клетки и живота, получавших лучевую терапию [35]. Путем случайной выборки пациенты были разделены на группы с включением 0,8 мг / мл инфликсимаба (основная группа) или без такового (контрольная группа). Содержание TGF- $\beta$ и TNF- $\alpha$ в образцах измерялось до и через 6, 12, 24, 48, 72, 96 ч после лучевой терапии. В крови пациентов контрольной группы до лучевой терапии было отмечено постоянное увеличение уровня TGF- $\beta$ вплоть до 96-го часа, после лучевой терапии уровень TGF- $\beta$ увеличивался в 3 раза к 48-му часу, затем незначительно снижался. В основной группе до лучевой терапии было отмечено нарастание уровня TGF- $\beta$ к 48-му часу с дальнейшим снижением вплоть до 96-го часа, после лучевой терапии - нарастание уровня TGF- $\beta$ к 6-му часу, резкий подъем - к 12-му часу и постоянное снижение вплоть до 96-го часа до уровня, лишь немногим более высокого, чем до лучевой терапии (при общих концентрациях на всех этапах ниже таковых в 2 раза в контрольной группе). Полученными in vitro результатами подтверждена гипотеза о снижении экспрессии TGF- $\beta$ путем инактивации TNF- $\alpha$ с помощью моноклональных антител. Также было доказано общее позитивное влияние инфликсимаба на содержание TNF- $\alpha$ в образцах крови: так, у пациентов контрольной группы после лучевой терапии уровень TNF- $\alpha$ был в 2 раза выше, чем его значения, зарегистрированные в образцах группы инфликсимаба до лучевой терапии.

Селективные ингибиторы циклооксигеназы-2 (целекоксиб) являются нестероидными противовоспалительными препаратами. В исследовании N.R.Hunter et al. [36] при облучении грудной клетки у мышей терапия целекоксибом проводилась в течение 40 последовательных дней 2 раза в день, начиная с момента облучения или 40-80 дней спустя. Значительное снижение пневмотоксичности и смертности было достигнуто только тогда, когда прием препарата был начат через 80 дней после лучевой терапии при наличии выраженных симптомов пневмонита. Что касается использования целекоксиба у людей, то в 1-й фазе клинических исследований [37] его назначали больным раком легкого $(n=18)$ одновременно с химиолучевой терапией по 200 или 400 мг в день, начиная за 5 дней до лучевой терапии и с последующей поддерживающей дозой в течение 12 нед. Отмечен менее выраженный пневмофиброз (т. е. поздняя токсичность) при приеме целекоксиба.
SOD - класс ферментов, которые играют одну из ключевых ролей в антиоксидантной защите организма. Низкомолекулярные миметики 3 типов SOD в исследованиях у животных проявили радиопротективное действие [38-41]. Так, SOD-миметик AEOL-10 113 вводился крысам интраперитонеально ежедневно в течение 5 дней в дозе 6 мг / кг за 15 мин до правосторонней лучевой терапии грудной клетки [42]. Показано, что у этих крыс по сравнению с животными, получившими только лучевую терапию, респираторный дистресс-синдром развивался реже и позже (у 1 из 9 животных на 14-й неделе после облучения vs 4 из 9 животных на 12-14-й неделе после облучения), отмечались значительное снижение уровня TGF- $\beta$ в плазме крови (особенно в поздние сроки), а также объема повреждения легких и степени тяжести фиброза $(3,5$ балла vs 5,9 балла по цифровой шкале от 0 до $8 ; p<0,05)$, что было подтверждено результатами гистологического исследования.

EUK-207 (Eukarion), также обладающий способностью ликвидировать активные формы кислорода, применялся у крыс путем ежедневной подкожной инъекции с момента начала и до 14-й недели после тотального облучения грудной клетки [43, 44]. Препарат обеспечил частичное смягчение симптомов лучевых повреждений легких в фазе пневмонита и поздней фазе фиброза (снижение уровня окислительного повреждения и количества активированных макрофагов), отмечен ограниченный эффект на экспрессию цитокинов.

Антиоксидантными свойствами обладает микроэлемент селен. A.Kunwar et al. исследовано действие производной селеноцистеина (DEePA) у мышей, часть из которых получала ее через 2 ч после облучения грудной клетки по 2 мг / кг 3 раза в неделю и в течение всего постлучевого периода до момента эвтаназии [45]. Выявлено, что в результате терапии DEePA уменьшено число тучных клеток, нейтрофилов и лимфоцитов в легких и жидкости бронхоальвеолярного лаважа (БАЛ), а также проявления пневмонита по сравнению с контрольной группой животных. В экспериментах у мышей И.С.Драчевым и соавт. установлено, что органические соединения селена на основе известных серосодержащих препаратов - цистеина и липоевой кислоты - более перспективны в качестве радиозащитных средств, чем неорганические (селениты кальция, марганца, стронция и лантана) [46]. Время, необходимое для достижения максимума радиопротективного действия, зависит от состояния окисления селена.

$\mathrm{B}$ опытах in vitro и in vivo с помощью витамина D стимулировалась пролиферация пневмоцитов 2-го типа и синтез сурфактанта, уменьшалась проницаемость сосудов и количество коллагенового геля. Радиопротективное действие витамина D было продемонстрировано у мышей, которым за 1 день до односторонней лучевой терапии грудной клетки вводился витамин $\mathrm{D}_{3}$ по 0,25 мкг / кГ / сутки в течение 8 нед. [47]. Микроскопическое исследование показало статистически значимые различия в уменьшении 
интерстициального воспаления, отложении коллагена и сохранении структуры альвеол облученного легкого по сравнению с контрольными группами животных.

Антиоксидантными свойствами обладают многие природные флавоноиды (класс растительных полифенолов). Показано радиопротективное и радиосмягчительное действие растительного полифенола куркумина у мышей, которым вводился его 5\%-ный раствор с пищей до и во время лучевой терапии [48]. По сравнению с контрольной группой, получавшей обычную диету и лучевую терапию, у животных отмечено уменьшение лучевого фиброза легких и повышение выживаемости. В работе [49] выявлено, что при ежедневном внутрижелудочном введении крысам в дозе 200 мг / кг в течение 1 нед. до однократного облучения грудной клетки и 8 нед. после действия куркумина смягчались симптомы лучевых повреждений легких. Макрофагальная инфильтрация легочной ткани, экспрессия провоспалительных цитокинов, утолщение альвеолярных перегородок, периваскулярный фиброз были менее выражены у животных основной группы.

В рандомизированном двойном слепом клиническом исследовании [50] изучалось действие берберина - алкалоида растительного происхождения. Больные немелкоклеточным раком легкого получали одновременно лучевую терапию и берберин $(n=42)$, а также лучевую терапию и плацебо $(n=43)$. Исследования содержания TGF- $\beta_{1}$ и sICAM-1 (растворимые молекулы межклеточной адгезии 1-го типа) в сыворотке крови, функции внешнего дыхания проводились в течение 6 мес. Установлено, что концентрации sICAM-1 и TGF- $\beta_{1}$ были значительно снижены на 6-й и 12-й неделях. В основной группе лучевые повреждения легких встречались через 6 нед. - у 45,2 \% пациентов и через 6 мес. - у 35,7 \% (в контрольной группе - 72,1 \% и 65, 1 \% случаев соответственно; $p<0,05)$.

В исследованиях $[44,51]$ при тотальном облучении легких у крыс в пищу животных основной группы добавлялось 750 мг / кг гинестеина (изофлавон сои). Показано, что действие гинестеина направлено на частичную защиту легких от развития ранней пневмотоксичности (пневмонита) на 6-10-й неделе после лучевой терапии, уменьшение степени пневмофиброза и увеличение сроков выживаемости животных на 50-80 дней.

При введении мышам интраперитонеально одновременно с лучевой терапией грудной клетки ингибитора TGF- $\beta$-сигнализации галофугинона - синтетического заменителя экстракта, полученного из растения Dichroa febrifuga, уменьшалась степень выраженности пневмофиброза [5, 6, 52].

Кверцетин (Flavin, Quercetol) - биофлавоноид, выделяемый из коры Quercus tinctoria, относится к группе витаминов Р. Лабораторными и гистологическими исследованиями доказано, что при введении мышам внутрибрюшинно до и после тотального облучения грудной клетки липосомальной формы кверцетина (липидные наноструктуры) уменьши- лись проявления радиационных острой пневмонии (пневмонита) и позднего пневмофиброза [53].

В исследовании [54] после однократного облучения грудной клетки мышам основной группы через желудочный зонд вводилась аминокислота таурин. Через 10 дней и 14 нед. после лучевой терапии измеряли содержание TGF- $\beta_{1}$ в сыворотке крови и жидкости БАЛ, гидроксипролина в легких. Указанные показатели были достоверно значительно ниже таковых в контрольной группе животных, что демонстрирует роль таурина в защите от развития радиационно-индуцированного фиброза легких.

Возможность использования в качестве радиопротекторов / митигаторов была изучена для ряда факторов роста. Рекомбинантный человеческий фактор роста кератиноцитов палифермин (Palifermin, Kepivance), в клинической практике применяется для уменьшения частоты и продолжительности тяжелого воспаление слизистой оболочки полости рта, вызванного химио- и радиотерапией, у пациентов со злокачественными заболеваниями крови. Доклиническими исследованиями у грызунов показано, что при введении 1 дозы палифермина после завершения курса фракционированного облучения грудной клетки значительно уменьшается тяжесть и продолжительность пневмонита и пневмофиброза [55]. Однако в связи со способностью палифермина значительно усиливать пролиферацию эпителиальных клеток [5, $15,55]$, что может быть небезопасно с онкологических позиций, требуются серьезные исследования по целесообразности его использования в предупреждении или лечении лучевых повреждений легких.

Проведено экспериментальное исследование средства, блокирующего TGF- $\beta_{1}$ [56]. Мыши были случайным образом разделены на 2 группы: получившие облучение грудной клетки (контрольная) и получившие интраперитонеально рекомбинантный аденовирус-опосредованный растворимый TGF- $\beta_{2}$ за 1 нед. до и 1 нед. после облучения. Было выявлено, что в последней группе концентрация TGF- $\beta_{1}$ в сыворотке крови и жидкости БАЛ была значительно снижена по сравнению с контрольной группой мышей, а при гистопатологическом исследовании отмечались лишь минимальные признаки лучевого пневмонита.

При введении мышам после облучения легких мочевого ингибитора трипсина (UTI, Ulinastatin) отмечено подавление экспрессии TGF- $\beta_{1}$ и снижение степени пневмофиброза. В результате на 30 -й неделе после лучевой терапии значительно повысилась выживаемость животных по сравнению с контрольной группой (33\% vs $10 \%$ соответственно; $p<0,05)$ [57].

В результате внутрибрюшинного введения мышам после облучения легких специфического ингибитора эластазы нейтрофилов (Sivelestat, Elaspol) на $18 \%$ увеличилась выживаемость за счет уменьшения лучевых повреждений легких (пневмонита) [58, 59].

Ингибитор протеинтирозинкиназы иматиниб (Glivec) - препарат, обладающий противоопухолевой активностью и использующийся в клинической практике в лечении хронического миелолейкоза, 
острого лимфобластного лейкоза, неоперабельных и / или метастатических злокачественных стромальных опухолей желудочно-кишечного тракта. При исследовании действия иматиниба у мышей показано существенное ослабление радиационно-индуцированного пневмофиброза при условии, что лечение начинается в момент облучения грудной клетки и продолжается во время периода острого воспаления (раннего пневмонита) [60]. Также было изучено позднее начало лечения иматинибом - препарат добавлялся в пищу через 3 дня (при остром воспалении) и через 14 дней (после стихания признаков острого воспаления) после тотального облучения грудной клетки у мышей. Результаты лечения оценивались по данным клинико-лабораторных, гистологических и томографических исследований in vivo. Доказано, что в результате обоих вариантов лечения уменьшается постлучевой пневмофиброз и увеличивается выживаемость животных, однако раннее начало приема иматиниба предпочтительнее.

\section{Заключение}

Лучевая терапия злокачественных новообразований органов грудной клетки вызывает радиационноиндуцированные повреждения легких. В результате снижается трудоспособность, качество жизни больных, возможен летальный исход. В настоящий момент возможности медикаментозного лечения данных осложнений весьма ограничены, поэтому задача профилактики, предупреждения и минимизации лучевых повреждений легких крайне актуальна, а для врачей-онкологов, радиологов, пульмонологов важна информация о медикаментозных средствах.

Существует большое количество лекарственных препаратов, обладающих радиопротективными свойствами, однако подавляющее большинство из них исследованы лишь экспериментально, поэтому многое еще предстоит сделать для разработки безопасных, минимально токсичных, эффективных и пригодных для клинического использования средств. Создание универсального радиопротектора - дело далекого будущего, и сочетанное применение лекарственных средств защиты от воздействия ионизирующего излучения не только отдельных органов, но и организма в целом могло бы стать предметом будущих исследований.

\section{Литература}

1. Ghafoori P., Marks L.B., Vujaskovic Z., Kelsey C.R. Radiation-induced lung injury. Assessment, management and prevention. Oncology 2008; 22 (1): 37-47.

2. Graves P.R., Siddiqui F., Anscher M.S., Movsas B. Radiation pulmonary toxicity: from mechanisms to management. Semin. Radiat. Oncol. 2010; 20 (3): 201-217.

3. Westbury C.B., Yarnold J.R. Radiation fibrosis - current clinical and therapeutic perspectives. Clin. Oncol. (Roy. Coll. Radiol.) 2012; 24 (10): 657-672.

4. Medhora M., Gao F., Jacobs E. R., Moulder J. E. Radiation damage to the lung: Mitigation by angiotensin-converting enzyme (ACE) inhibitors. Respirology 2012; 17 (1): 66-71.
5. Citrin D., Cotrim A.P., Hyodo F. et al. Radioprotectors and mitigators of radiation-induced normal tissue injury. Oncologist 2010; 15: 360-371.

6. Patel V.N., Gupta S., Shareef M.M., Ahmed M.M. Contemporary radiation countermeasures. Defence Sci. J. 2011; 61 (2): $138-145$.

7. Movsas B., Vikram B., Hauer-Jensen M. et al. Decreasing the adverse effects of cancer therapy: National Cancer Institute Guidance for the Clinical Development of Radiation Injury Mitigators. Clin. Cancer Res. 2011; 17 (2): 222-228.

8. Васин М.В. Классификация противолучевых средств как отражение современного состояния и перспективы развития радиационной фармакологии. Радиационная биология. Радиоэкология 2013; 53 (5): 459-467.

9. Стюарт Ф.А., Аклеев А.В., Хауэр-Дженсен М. и др. Отчет МКРЗ по тканевым реакциям, ранним и отдаленным эффектам в нормальных тканях и органах - пороговые дозы для тканевых реакций в контексте радиационной защиты (Труды МКР3; публикация 118): Пер. с англ. Под ред. А.В.Аклеева, М.Ф.Киселева. Челябинск: Книга 2012.

10. Antonadou D., Coliarakis N., Synodinou M. et al. Randomized phase III trial of radiation treatment / amifostine in patients with advanced-stage lung cancer. Int. J. Radiat. Oncol. Biol. Phys. 2001; 51: 915-922.

11. Antonadou D., Petridis A., Synodinou M. et al. Amifostine reduces radiochemotherapy-induced toxicities in patients with locally advanced non-small cell lung cancer. Semin. Oncol. 2003; 30 (6, Suppl. 18): 2-9.

12. CTEP Common Toxicity Criteria, Version 2.0 DCTD, NCI, NIH, DHHS, March 1998: 24; app IV: 32.

13. Komaki R., Lee J.S., Kaplan B. et al. Randomized phase III study of chemoradiation with or without amifostine for patients with favorable performance status inoperable stage II-III non-small cell lung cancer: Preliminary results. Semin. Radiat. Oncol. 2002; 12 (Suppl. 1): 46-49.

14. Marks L.B., Yu X., Vujaskovic Z. Radiation-induced lung injury. Semin. Radiat. Oncol. 2003; 13: 333-345.

15. Tsoutsou P.G., Koukourarakis M.I. Radiation pneumonitis and fibrosis: mechanism underlying its pathogenesis and implications for future researche. Int. J. Radiat. Oncol. Biol. Phys. 2006; 66 (5): 1281-1293.

16. Movsas B., Scott C., Langer C. et al. Randomized trial of amifostine in locally advanced non-small-cell lung cancer patients receiving chemotherapy and hyperfractionated radiation: Radiation Therapy Oncology Group trial 98-01. J. Clin. Oncol. 2005; 23: 2145-2154.

17. Ozturk B., Egehan I., Atavci S., Kitapci M. Pentoxifylline in prevention of radiation-induced lung toxicity in patients with breast and lung cancer: a double-blind randomized trial. Int. J. Radiat. Oncol. Biol. Phys. 2004; 58: 213-219.

18. Delanian S., Porcher R., Balla-Mekias S., Lefaix J.-L. Randomized, placebo-controlled trial of combined pentoxifillin and tocopherol for regression of superficial radiationinduced fibrosis. J. Clin. Oncol. 2003; 21 (13): 2545-2550.

19. Jacobson G., Bhatia S., Smith B.J., Button A.M. Randomized trial of Pentoxifylline and Vitamin E vs standard follow-up after breast irradiation to prevent breast fibrosis, evaluated by tissue compliance meter. Int. J. Radiat. Oncol. Biol. Phys. 2013; 85 (3): 604-608.

20. Moulder J.E., Cohen E.P. Future strategies for mitigation and treatment of chronic radiation-induced normal tissue injury. Semin. Radiat. Oncol. 2007; 17: 141-148.

21. Molteni A., Moulder J.E., Cohen E.F. et al. Control of radiation-induced pneumopathy and lung fibrosis by angiotensin-converting enzyme inhibitors and an angiotensin II 
type 1 receptor blocker. Int. J. Radiat. Biol. 2000; 76 (4): 523-532

22. Molteni A., Wolfe L.F., Ward W.F. et al. Effect of an angiotensin II receptor blocker and two angiotensin converting enzyme inhibitors on transforming growth factor-beta (TGF- $\beta$ ) and alpha-actomyosin (alpha SMA), important mediators of radiation-induced pneumopathy and lung fibrosis. Curr. Pharm. Des. 2007; 13: 1307-1316.

23. Ghosh S.N., Zhang R., Fish B.L. et al. Renin-Angiotensin system suppression mitigates experimental radiation pneumonitis. Int. J. Radiat. Oncol. Biol. Phys. 2009; 75 (5): $1528-1536$.

24. Medhora M., Gao F., Fish B.L. et al. Dose-modifying factor for captopril for mitigation of radiation injury to normal lung. J. Radiat. Res. 2012; 53 (4): 633-640.

25. Molthen R.C., Wu Q., Fish B.L. et al. Mitigation of radiation induced pulmonary vascular injury by delayed treatment with captopril. Respirology 2012; 17 (8): 1261-1268. doi: 10.1111/j.1440-1843.2012.02247.x.

26. Williams J.P., Jackson I.L., Shah J.R. et al. Animal models and medical countermeasures development for radiationinduced lung damage: Report from an NIAID Workshop. Radiat. Res. 2012; 177: e0025-e0039. doi: 10.1667/RROL04.1

27. Kharofa J., Cohen E.P., Tomic R. et al. Decreased risk of radiation pneumonitis with incidental concurrent use of angiotensin-converting enzyme inhibitors and thoracic radiation therapy. Int. J. Radiat. Oncol. Biol. Phys. 2012; 84 (1): $238-243$.

28. Williams J.P, Johnston C.J., Finkelstein J.N. Treatment for radiation-induced pulmonary late effects: Spoiled for choice or looking in the wrong direction? Curr. Drug Targets 2010; 11 (11): 1386-1394.

29. Sun X.F., Wang L.L., Wang J.K. et al. Effects of simvastatin on lung injury induced by ischaemia-reperfusion of the hind limbs in rats. J. Int. Med Res. 2007; 35: 523-533.

30. Yao H.W., Mao L.G., Zhu J.P. Protective effects of pravastatin in murine lipopolysaccharide-induced acute lung injury. Clin. Exp. Pharmacol. Physiol. 2006; 33: 793-797.

31. Xia D.H., Xi L., Xy C. et al. The protective effects of ambroxol on radiation lung injury and influence on production of transforming growth factor beta1 and tumor necrosis factor alpha. Med. Oncol. 2010; 27 (3): 697-701. doi:10.1007/ s12032-009-9271-3.

32. Demedts M., Behr J., Buhl R. et al. High-dose Acetylcysteine in idiopathic pulmonary fibrosis. N. Engl. J. Med. 2005; 353: 2229-2242.

33. Noble P.W., Albera C., Bradford W.Z. et al. Pirfenidone in patients with idiopathic pulmonary fibrosis (CAPACITY): two randomised trials. Lancet 2011; 377 (9779): 1760-1769.

34. Bargagli E., Galeazzi M., Bellisai F. et al. Infliximab treatment in a patient with systemic sclerosis associated with lung fibrosis and pulmonary hypertension. Respir. Intern. Rev. Thorac. Dis. 2008; 75 (3): 346-349.

35. Staroslawska E., Czarnocki K. J., Koziol-Montewka M. et al. Effect of infliximab on the levels of TNF- $\alpha$ and TGF- $\beta$ in the whole blood cultures of irradiated patients. Folia Histochem. Cytobiol. 2008; 46 (3): 291-297.

36. Hunter N.R., Valdecanas D., Liao Z. et al. Mitigation and treatment of radiation-induced thoracic injury with a cyclooxygenase-2 inhibitor, celecoxib. Int. J. Radiat. Oncol. Biol. Phys. 2013; 85 (2): 472-476. doi: 10.1016/j.ijrobp.2012. 04.025 .

37. Komaki R., Wei X., Allen P.K. et al. Phase I study of Celecoxib with concurrent Irinotecan, Cisplatin, and radiation therapy for patients with unresectable locally advanced non- small cell lung cancer. Front. Oncol. 2011; 1: 52. Published online 2011 December 13.

38. Epperly M., Bray J., Kraeger S. et al. Prevention of late effects of irradiation lung damage by manganese superoxide dismutase gene therapy. Gene Ther. 1998; 5: 196-208.

39. Lefaix J.-L., Delanian S., Leplat J.J. et al. Successful treatment of radiation-induced fibrosis using $\mathrm{Cu} / \mathrm{Zn}-\mathrm{SOD}$ and Mn-SOD: An experimental study. Int. J. Radiat. Oncol. Biol. Phys. 1996; 35: 305-312.

40. Kang S.K., Rabbani Z.N., Folz R.J. et al. Overexpression of extracellular superoxide dismutase protects mice from radiation-induced lung injury. Int. J. Radiat. Biol. Oncol. Phys. 2003; 47: 1056-1066.

41. Rabbani Z.N., Anscher M.S., Folz R.J. et al. Overexpression of extracellular superoxide dismutase reduces acute radiation induced lung toxicity. BMC Cancer 2005; 5: 59. doi:10.1186/1471-2407-5-59.

42. Vujaskovic Z., Batinic-Haberle I., Rabbani Z.N. et al. A small molecular weight catalytic metalloporphyrin antioxidant with superoxide dismutase (SOD) mimetic properties protects lungs from radiation-induced injury. Free Radic. Biol. Med. 2002; 33: 857-863.

43. Mahmood J., Jelveh S., Calveley V. et al. Mitigation of radiation-induced lung injury by genistein and EUK-207. Int. J. Radiat. Biol. 2011; 87 (8): 889-901.

44. Mahmood J., Jelveh S., Zaidi A. et al. Mitigation of radiation-induced lung injury with EUK-207 and genistein: effects in adolescent rats. Radiat. Res. 2013; 179 (2): 125-134.

45. Kunwar A., Jain V.K., Priyadarsini K.I., Haston C.K. A Selenocysteine Derivative therapy affects radiation-induced pneumonitis in the mouse. Am. J. Respir. Cell. Mol. Biol. 2013; 49 (4): 654-661.

46. Драчев И.С., Легеза В.И., Турлаков Ю.С. Перспективы применения соединений селена в качестве радиопротекторов. Радиац. биол. радиоэкол. 2013; 53 (5): 475-480.

47. Yazici G., Yildis F., Iskit A. et al. The effect of vitamin D prophylaxis on radiation induced pulmonary damage. J. Radiat. Res. 2011; 52 (5): 616-621.

48. Lee J.C, Kinniry P.A., Arguiri E. et al. Dietary curcumin increases antioxidant defenses in lung, ameliorates radiation-induced pulmonary fibrosis, and improves survival in mice. Radiat. Res. 2010; 173 (5): 590-601.

49. Cho Y.J., Yi Ch.O., Jeon B.T. et al. Curcumin attenuates radiation-induced inflammation and fibrosis in rat lungs. Korean J. Physiol. Pharmacol. 2013; 17 (4): 267-274. English. Published online 2013 July 30.

50. Liu $Y$., Yu H., Zhang $C$. Protective effects of berberine on radiation-induced lung injury via intercellular adhesion molecular-1 and transforming growth factor-beta- 1 in patients with lung cancer. Eur. J. Cancer 2008; 44: 2425-2432.

51. Calveley V.L., Jelveh S., Langan A. et al. Genistein can mitigate the effect of radiation on rat lung tissue. Radiat. Res. 2010; 173 (5): 602-611.

52. Xavier S., Piek E., Fujii M. et al. Amelioration of radiationinduced fibrosis: inhibition of transforming growth factorbeta signalling by halofuginone. J. Biol. Chem. 2004; 279 (15): 15167-15176.

53. Liu H., Хие J.X., Li X. et al. Quercetin liposomes protect against radiation-induced pulmonary injury in a murine model. Oncol. Lett. 2013; 6 (2): 453-459.

54. Robb W.B., Condron C., Moriarty M. et al. Taurine attenuates radiation-induced lung fibrosis in C57/B16 fibrosis prone mice. Irish J. Med. Sci. 2010; 179 (1): 99-105. 
55. Brizel D.M. Pharmacologic approaches to radiation protection. J. Clin. Oncol. 2007; 25 (26): 4084-4089.

56. Haiping Z., Takayama K., Uchino J. et al. Prevention of radiation-induced pneumonitis by recombinant adenovirusmediated transferring of soluble TGF-beta type II receptor gene. Cancer Gene Ther. 2006; 13 (9): 864-872.

57. Katoh H., Ishikawa H., Hasegava M. et al. Protective effect of urinary trypsin inhibitor on the development of radiationinduced lung fibrosis in mice. J. Radiat. Res. 2010; 51 (3): 325-332.

58. Shimbo T., Inomata T., Takahashi M.et al. Effects of sivelestat sodium hydrate on the reduction of radiation pneumonitis. Int. J. Mol. Med. 2007; 20 (6): 817-822.

59. Fox J., Haston C.K. CXC receptor 1 and 2 and neutrophil elastase inhibitors alter radiation-induced lung disease in the mouse. Int. J. Radiat. Oncol. Biol. Phys. 2013; 85 (1): 215-222. doi: 10.1016/j.jirobp.2012.02.024.
60. Li M., Abdollahi A., Grone H.L. et al. Late treatment with imatinib mesylate ameliorates radiation-induced lung fibrosis in a mouse model. Radiat. Oncol. 2009; 4: 66. Published online 2009 December 21.

\section{Информация об авторах}

Сычева Марина Генриховна - к. м. Н., ст. научный сотрудник отдела реабилитации больных с заболеваниями бронхолегочной системы ГБУ "Московский научно-практический центр медицинской реабилитации, восстановительной и спортивной медицины" Департамента здравоохранения Москвы; тел.: (916) 974-68-63; e-mail: sytchevameister @gmail.com

Грушина Татьяна Ивановна - д. м. н., руководитель отдела медицинской реабилитации онкологических больных, ГБУ "Московский научнопрактический центр медицинской реабилитации, восстановительной и спортивной медицины" Департамента здравоохранения Москвы; тел.: (916) 774-19-39; e-mail: tgrushina@gmail.com

Поступила 12.12.13 ( Сычева М.Г., Грушина Т.И., 2013 удк 616.24-001.29-084 